\title{
Health-related quality of life before planned admission to intensive care: memory over three and six months
}

\author{
Maurizia Capuzzo ${ }^{1 *}$, Sara Bertacchini ${ }^{1}$, Elena Davanzo ${ }^{1}$, Giovanna Felisatti ${ }^{1}$, Laura Paparella², Laura Tadini ${ }^{3}$
} Raffaele Alvisi ${ }^{1}$

\begin{abstract}
Background: The validity of Health-Related Quality of Life (HRQOL) recalled by ICU admitted patients have not been published. The aim of this study was to compare the baseline HRQOL measured before surgery and ICU admission with that recalled at 3 and 6 months in a population of patients with planned ICU admission after surgery.
\end{abstract}

Methods: This prospective study was performed in three Italian centres on patients who had undergone General Orthopaedic or Urologic surgery. All adult patients with planned ICU admission between October 2007 and July 2008 were considered for enrolment. At hospital admission, the Mini Mental Status Examination and EuroQoL (EQ) questionnaire (referring to the last two weeks) were administered to the patients who consented. Three and six months after ICU admission, the researchers administered by phone the EQ questionnaire and Post-Traumatic Stress Syndrome 14 questions Inventory, asking the patients to rate their HRQOL before surgery and ICU admission. Past medical history demographic and clinical ICU-related variables were collected.

Statistical analysis: Chi-square test and non parametric statistics were used to compare groups of patients. The EQ-5D was transformed in the time trade-off (TTO) to obtain a continuous variable, subsequently analysed using the Intraclass Correlation Coefficient (ICC).

Results: Of the 104 patients assessed at baseline and discharged from the hospital, 93 had the EQ administered at 3 months, and 89 at 6 months. The ICC for TTO recalled at 3 months vs pre-ICU TTO was 0.851, and that for TTO recalled at 6 months vs pre-ICU TTO was 0.833. The ICC for the EQ-VAS recalled at 3 months vs pre-ICU EQ-VAS was 0.648 , and that for the EQ-VAS recalled at 6 months vs pre-ICU EQ-VAS was 0.580 . Forty-two (45\%) patients assessed at 3 months gave the same score in all EQ-5D items as at baseline. They underwent mainly orthopaedic surgery ( $p$ 0.011), and perceived the severity of their illness as lower ( $p$ 0.009) than patients scoring differently at 3 months in comparison with baseline.

Conclusions: The patients with planned ICU admission have a good memory of their health status as measured by EQ-5D in the period preceding surgery and ICU admission, especially at three months.

\section{Background}

Health-related Quality of Life (HRQOL) of the patients admitted to Intensive Care Unit (ICU) is one of the most relevant outcome measures for patients, families, physicians and society. To understand the clinical

\footnotetext{
* Correspondence: cpm@unife.it

'University Section of Anaesthesiology and Intensive Care, Azienda Ospedaliero-Universitaria di Ferrara Arcispedale S. Anna, Ferrara, Italy Full list of author information is available at the end of the article
}

meaning of HRQOL in ICU survivors, we should make comparisons, either with the HRQOL of the matched general population or with the patient HRQOL before ICU admission [1].

Considering that baseline HRQOL of ICU patients has been shown to be significantly lower than that of the matched general population [2-5], it appeared wise for researchers to compare post-ICU with baseline HRQOL [2-4,6]. However, most of the ICU admissions are

\section{() Biomed Central}


unpredictable, so baseline HRQOL can be measured only a posteriori in those patients who are asked about their HRQOL in the period of two [7] or three [6,8] months before ICU admission. Nevertheless, asking patients to recall and rate a previous HRQOL may introduce a recall bias since patients may not accurately remember their status prior to critical illness [9-11], their evaluation being influenced by the present status. We have only found one study considering patients admitted to the hospital with chest pain where researchers assessed the ability of respondents to recall their pre-hospital admission HRQOL [12]. In that study, six generic health status questionnaires were self-administered to the patients during hospital stay and mailed home three months after hospital discharge. The assessments were generally similar, but some patients reported that they were more functional before ICU admission in mental well-being, work and housework performance at the assessment performed at three months than in that performed during hospital stay [12]. Nothing is known about the "memory stability" of baseline HRQOL in patients admitted to ICU.

Some patients undergoing scheduled surgical procedures are admitted to ICU due to their poor clinical conditions and/or to type and magnitude of surgery. They are a group of ICU patients suitable for the on time assessment of HRQOL before ICU admission.

Therefore we designed a study to compare the baseline HRQOL measured before surgery and ICU admission with that recalled at 3 and 6 months in a population of patients with planned ICU admission after general, orthopaedic and urologic scheduled surgery.

\section{Methods}

The study was performed in three Italian hospitals on patients who had undergone General and Orthopaedic and Urologic surgeries, respectively. The Hospital Ethics Committees approved the study protocol and written consent was obtained from the enrolled patients. All consecutive adult patients where ICU admission was planned at the time of the anaesthetic visit between October 2007 and July 2008 were considered for enrolment. The criteria for inclusion in the study were age $>18$ years, ability to co-operate and consent to the study. Patients not aware of self and environment were excluded, as well as those refusing to participate.

At the preoperative anaesthetic visit of a patient who was a potential candidate for ICU postoperative admission, the physician informed the patient about the study. At hospital admission, the researchers administered the Mini Mental Status Examination [13] and EuroQoL questionnaire $[14,15]$ referring to the last two weeks to the patients who consented (pre-ICU assessment). Additionally, a structured form was used to collect information about the following variables: gender, age, number of years of education, smoking habits (never smoker, former smoker and current smoker), alcohol habits (not used, only occasionally, daily), regular taking of benzodiazepines, beta-blockers, and antihypertensive drugs. Moreover, the following information was collected for each patient: type of surgery and anaesthesia, a severity of illness score (Simplified Acute Physiology Score SAPS II [16]), length of stay (LOS) as number of days in ICU and in hospital after ICU discharge, number of hours on mechanical ventilation, analgesic and sedative drugs administrated during ICU stay, presence of delirium, assessed by the Confusion Assessment Method for the Intensive Care Unit [17] and number of days in delirium.

Three and six months after ICU admission, the same researcher who administered the EuroQoL questionnaire in hospital administered it by phone, asking the patients to rate their HRQOL before surgery and ICU admission. Then, the patients were asked whether their present health status was the same, better, or worse compared with that before surgery and ICU admission.

Moreover, during the same phone call, the researchers administered the Post-Traumatic Stress Syndrome 14 questions Inventory [18].

A minimum of 22 patients per centre were required assuming correlation coefficients would be obtained of over 0.75 with a significance level of 0.01 and a power of 0.80 . Considering a projected $10 \%$ loss or withdrawal rate, each centre was invited to collect at least 30 patients.

\section{Instruments used in the study \\ Mini Mental Status Examination}

The Mini Mental Status Examination (MMSE) was administered to evaluate global cognitive functions, such as orientation in space and time, concentration and attention span, immediate and delayed verbal memory, constructive praxis and language [13]. The final score was adjusted according to the classes of age and education [19]. The results of the MMSE are expressed as a score ranging from 0 to 30 .

\section{EuroQol}

The questionnaire administered was EuroQol (EQ). It is a generic questionnaire, easy to administer and consists of two parts. In the first part (EQ-5D), five dimensions (mobility, self-care, usual activities, pain/discomfort, and anxiety/depression) are considered, and, for each, a question is posed with three possible answers: no problems; some/moderate problems; severe/extreme problems. A health state is a combination of one level for each dimension, with 243 possible health states. Preferences have been assessed using time trade-off (TTO) of a subset of health states from a UK population [20]. In the reworked TTO scale the logically best health 
state (no problem in any of the five dimensions) has the value of 1 , while death has the value 0 [21]. Nevertheless, due to the possible presence of a negative factor in the model, there are also states with values lower than 0 . In the second part of the EQ (EQ-VAS), the patients are asked to rate their health status on a scale from 100 (the best imaginable health status) to 0 (the worst imaginable health status).

The validity and reliability of the EQ have been tested in the ICU population, and it has been recommended for use in critical care [11]. It was designed for self-completion [15] but it was also administered by telephone $[6,22]$ or by direct interview [23].

Because the EQ VAS was administered by telephone, the results could not be graphically represented on a $20-\mathrm{cm}$ line, as originally proposed. Therefore, EQ VAS was recorded as a numerical rating from 100 (best health status) to 0 (worst health status).

Confusion Assessment Method for the Intensive Care Unit The Confusion Assessment Method for the Intensive Care Unit (CAM-ICU) [17] assesses the presence or the absence of the following four features: 1) acute onset of mental status changes or a fluctuating course; 2) inattention; 3) disorganized thinking; 4) altered level of consciousness (i.e. other than alert). The patients are diagnosed as having delirium (i.e. CAM positive) if both features 1 and 2 and either feature 3 or 4 are present.

The CAM-ICU can be administered by doctors or nurses. It has been developed to be used in mechanically ventilated patients and is one of the most commonly used instruments for delirium [24].

\section{Post-Traumatic Stress Syndrome 14 questions Inventory}

The Post-Traumatic Stress Syndrome 14 questions Inventory (PTSS-14) [18] is composed of two parts: part A (assessment of traumatic memories from the ICU) and part B (post-traumatic stress disorder symptoms). Part A of the questionnaire consists of a structured survey asking for possible traumatic experiences during ICU treatment (patient's subjective memory of respiratory distress/dyspnoea, feelings of severe anxiety/panic, severe pain, or nightmares). Patients are asked to answer whether (yes or no) they remember each of four items. Part B evaluates 14 PTSD symptoms (sleep problems, nightmares, depression, jumpiness, need for withdrawal, irritability, frequent mood swings, bad conscience, fear of place and situation, muscular tension, upsetting/ unwanted thoughts or image of the time on ICU, feeling numb, avoiding places/people or situations that remind them of the ICU, feeling as though plans or dreams for the future will not come true). When completing the questionnaire, the patients rate their symptoms using a scale from 1 (never) to 7 (always) and sum score ranging from 14 to 98 points is calculated. A total score of more of 45 points has been reported to be predictive of PTSD [18].

\section{Perceived severity of illness}

The severity of illness as perceived by the patient was assessed at 3 months using a verbal Numerical Rating Scale (NRS) ranging from 0 to 10 . The investigator asked the patient to indicate the perceived level of his/ her severity of illness at the time of ICU stay, saying "Please, tell me how serious your clinical conditions were while in ICU, using a scale where 0 means «not serious» and 10 means «as serious as possible».

\section{Statistical Analysis}

The data are expressed as median with Inter Quartile Range (IQR). Categorical variables are described as absolute numbers with percentages. Statistical analysis was carried out using a software package (SPSS 11.5 Chicago, Illinois, USA) and two-tailed p-values less than 0.05 were selected as significant. The Chi-square test, or Fisher Exact test, when appropriate, was used for categorical variables. The Kolmogorov-Smirnov test showed that most of the continuous variables were not normally distributed, so they were analysed using Mann-Whitey and Kruskall-Wallis statistics.

To evaluate the reliability of the patients' memory of HRQOL at 3 and 6 months after ICU admission, in comparison with that assessed before surgery and ICU admission, we transformed the EQ-5D in the time trade-off (TTO) as assessed according to a subset of health states from a UK population [20]. This made the EQ-5D a continuous variable, which was subsequently analysed using the Intraclass Correlation Coefficient (ICC), two-way mixed average measures model (consistency). The EQ-VAS, which was also a continuous variable, was analysed in the same way. The ICC measures agreement from 0 or less (no agreement) to 1 (perfect agreement), with a good to excellent agreement for values $>0.6$ according to the Fleiss' rules [25].

A forward stepwise logistic regression analysis was performed to determine which variables pertinent to the patients were independently associated with the same rating of HRQOL before surgery and ICU admission, and at 3 months. To make the dependent variable categorical the comparison between the EQ-5D scored before surgery and ICU admission and that scored at 3 months was categorized as the "same" when there was no difference between any items, and "different" when at least one EQ-5D item at 3 months was different in comparison with that before surgery and ICU admission. Factors that were significant for a $\mathrm{p}$ value $<0.20$ in the univariate analyses were entered into the multivariate stepwise logistic regression analysis. Odds ratio were 
estimated from b coefficients and expressed with 95\% Confidence Interval (95\% CI).

\section{Results}

During the study period 152 patients undergoing surgery and planned to be admitted to the study ICUs consented to participate. Of these, 39 were not subsequently admitted to the ICU due to a less aggressive surgical procedure than previously supposed. Of the remaining 113 patients, 2 died in ICU and 7 died in hospital after discharge. Therefore 104 patients admitted to ICU after planned surgery were discharged from the hospital. Nine of them refused to take part in the subsequent phase of the study, one was lost despite multiple attempts to find her and one was admitted to another hospital and was only administered the questionnaire after 6 months. The final group consisted of 93 patients having the EQ questionnaire administered at 3 months and 89 at 6 months (flow-chart in figure 1).

The 94 patients included at any time in the study underwent the following kind of surgery: general including major gastrointestinal surgery (14 patients), thoracic surgery (5), esophagectomy (4), and abdominal aortic surgery (2); orthopaedic including hip prosthesis (20 patients), knee prosthesis (6) and major osteosynthesis (7); and urologic including nephrectomy (13 patients), cystectomy (9), prostatectomy (9) and other (5). The demographic and clinical characteristics of the study patients are reported in table 1 . The mean TTO according to the EQ-5D assessed at the time of the preoperative visit was 0.596 (95\% CI $0.535-0.658)$, the mean TTO recalled at 3 months was 0.581 (95\% CI 0.522 $0.639)$, and that recalled at 6 months was $0.601(95 \% \mathrm{CI}$ 0.544-0.658). The ICC for TTO recalled at 3 months vs pre-ICU TTO was 0.851, and that for TTO recalled at 6 months vs pre-ICU TTO was 0.833 . The mean EQ-VAS assessed at the time of the preoperative visit was 48.7 (95\% CI 45.7-51.7), that recalled at 3 months was 49.4 (95\% CI $45.9-52.8$ ), and that recalled at 6 months was 51.6 (95\%CI 47.8-55.3). The ICC for the EQ-VAS recalled at 3 months vs pre-ICU EQ-VAS was 0.648 , and that for the EQ-VAS recalled at 6 months vs pre-ICU EQ-VAS was 0.580 . The percentages of patients reporting any problems in EuroQol-5D at the pre-ICU assessment, and recalling any problems at the assessments performed at 3 and 6 months are reported in Figure 2.

To investigate the effect of prolonged ICU LOS on recall, the reliability of EQ-5D and EQ VAS recalled at 3 months by the 64 patients with an ICU LOS lower or equal to the median value ( 2 days) and by the 29 patients staying in ICU more than 2 days were analysed. The demographic and clinical characteristics of those two group patients are reported in table 2 . In the patients with ICU LOS $\leq 2$ days, the ICC for TTO recalled at 3 months vs pre-ICU TTO was 0.872 , and that for TTO recalled at 6 months vs pre-ICU TTO was 0.832. The median EQ-VAS assessed at the time of the preoperative visit was 50 (IQR 40-50), that recalled at 3 months was 50 (IQR 40-50), and that recalled at 6 months was 50 (IQR 40-60). The ICC for the EQ-VAS recalled at 3 months vs pre-ICU EQ-VAS was 0.612, and that for the EQ-VAS recalled at 6 months vs preICU EQ-VAS was 0.569. In the patients with ICU LOS $>2$ days, the ICC for TTO recalled at 3 months vs preICU TTO was 0.765 , and that for TTO recalled at 6 months vs pre-ICU TTO was 0.823 . The median EQVAS assessed at the time of the preoperative visit was 50 (IQR 40-60), that recalled at 3 months and that recalled at 6 months were exactly the same. The ICC for the EQ-VAS recalled at 3 months vs pre-ICU EQVAS was 0.698 , and that for the EQ-VAS recalled at 6 months vs pre-ICU EQ-VAS was 0.765 .

The percentages of patients who gave the same answer at 3 months as that given pre-ICU were $89 \%$ for EQ-5D dimension of mobility, $91 \%$ for self-care, $87 \%$ for usual activities, $72 \%$ for pain/discomfort, and 78\% for anxiety/ depression. Similar results were found for the answers given at 6 months, with percentages of $89 \%$ for mobility and for self care, $83 \%$ for usual activities, $65 \%$ for pain/ discomfort and $84 \%$ for anxiety/depression, respectively. The differences between pre-ICU EQ-5D recorded at 3 months and EQ-5D given before ICU admission and between pre-ICU EQ-5D recorded at 6 months and EQ-5D given before ICU admission, for each dimension are reported in Figure 3 and 4, respectively. In the figures, the differences were calculated for each item as the value remembered at 3 months minus the value given before ICU admission: for instance, a patient who remembered having an EQ-5D for mobility of 1 (no problems) at 3 months and scored 2 (some problems) before ICU admission was considered as having a difference of -1 , meaning that he/she recalled a better past mobility than that previously assessed.

Out of the 93 patients assessed at 3 months, 42 (45\%) gave the same score in all EQ-5D items as before surgery and ICU admission. At the univariate analysis (Table 3), more patients who reported at 3 months the same scoring in all EQ-5D items as before surgery and ICU admission underwent orthopaedic surgery ( $p$ 0.011) and perceived the severity of their illness lower or equal 5 (p 0.009) than the patients scoring differently at 3 months in at least one EQ-5D item.

Two of the variables entered in the logistic regression analysis (use of antidepressants, use of beta-blockers, General, Orthopaedic or Urologic surgery, mechanical ventilation while in ICU, and perceived severity of illness categorized as $\leq$ or $>5$ in NRS $0-10$ ) were significantly 


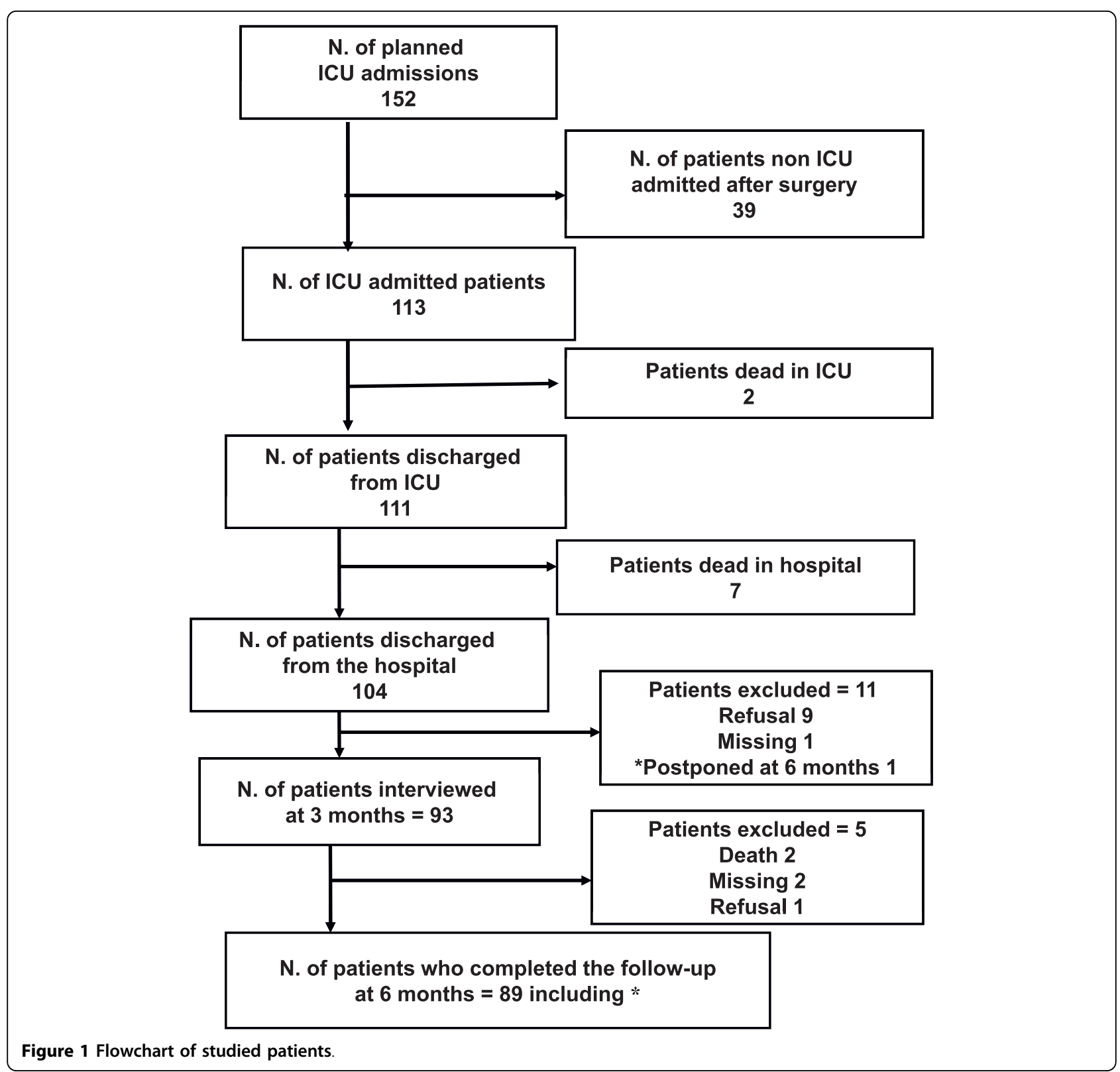

associated with reliability of EQ-5D assessment at 3 months (lack of any difference in all items between the EQ-5D assessed before surgery and ICU admission and that recalled 3 month after ICU discharge). The general surgery patients showed a significantly poorer ability to recall pre-ICU EQ-5D (Odds Ratio 0.192 with 95\%CI 0.062-0.590; p 0.004). The chronic use of beta-blockers was directly associated with better ability to recall pre-ICU EQ-5D (Odds Ratio 3.457 with 95\%CI 1.159-10.313; p 0.026). To investigate whether the ICU LOS ( $\leq$ or $>2$ days) influences the pre-ICU EQ-5D recall, we tried to include this variable in the model, but it was not relevant.

The patients were grouped also according to the answers given at 6 months in comparison with those given before ICU admission: 41 gave same answers and 48 gave different answers. The univariate analysis showed that the following variables were different at a p level

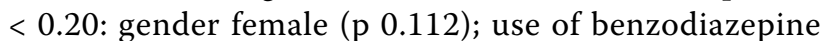
(p 0.170); use of beta-blockers (0.014); no alcohol habit (0.152); type of surgery (p 0.007); SAPS II with a cut-off value of 30 ( $p$ 0.057) and perceived severity of illness at 6 months with 5 as cut-off (p0.023). A new logistic regression analysis was performed using those variables and three variables were included in the final model. Both the general surgery and urologic surgery patients showed a significantly poorer ability to recall pre-ICU EQ-5D (Odds Ratio 0.144 with 95\%CI 0.039-0.525; p 0.003, and Odds Ratio 0.328 with 95\%CI 0.116-0.922; 
Table 1 Demographic and clinical characteristics of the study patients

\begin{tabular}{|c|c|c|}
\hline Number of patients & 93 & \\
\hline Number of males & 64 & $68.8 \%$ \\
\hline Age (years) median (IQR) & 74 & $(66-78)$ \\
\hline Education (years): $<8$ & 33 & $35.4 \%$ \\
\hline $8-13$ & 53 & $60.6 \%$ \\
\hline$>13$ & 7 & $7.5 \%$ \\
\hline MMSE adjusted median (IQR) & 26 & $(25-28)$ \\
\hline Use of any benzodiazepines & 11 & $11.8 \%$ \\
\hline Use of any antidepressants & 8 & $8.6 \%$ \\
\hline Use of antihypertensive drugs & 78 & $83.8 \%$ \\
\hline Use of B-blockers & 22 & $23.6 \%$ \\
\hline Use of any statins & 24 & $25.8 \%$ \\
\hline Smoking habits: no & 25 & $26.9 \%$ \\
\hline former & 55 & $59.1 \%$ \\
\hline yes & 13 & $14.0 \%$ \\
\hline Alcohol: no & 49 & $52.6 \%$ \\
\hline sometimes & 31 & $33.4 \%$ \\
\hline every day & 13 & $14.0 \%$ \\
\hline Type of surgery: General & 24 & $25.8 \%$ \\
\hline Orthopaedic & 33 & $35.4 \%$ \\
\hline Urologic & 36 & $38.8 \%$ \\
\hline Type of anaesthesia: regional \pm general & 19 & $20.5 \%$ \\
\hline general & 74 & $79.5 \%$ \\
\hline \multicolumn{3}{|l|}{ ICU and hospital course } \\
\hline SAPS II median (IQR) & 29 & $(24-43)$ \\
\hline Number of patients ventilated & 41 & $44.0 \%$ \\
\hline Duration of ventilation (h) median (IQR) & 6 & $(4-19)$ \\
\hline Number of patients with delirium in ICU & 6 & $6.4 \%$ \\
\hline ICU LOS (days) median (IQR) & 2 & $(1-3)$ \\
\hline Hospital LOS ${ }^{a}$ (days) median (IQR) & 7 & $(5-10)$ \\
\hline
\end{tabular}

${ }^{a}$ LOS: Length of stay p 0.035 , respectively). The chronic use of beta-blockers was again directly associated with better ability to recall pre-ICU EQ-5D (Odds Ratio 4.431 with 95\%CI 1.37314.304; p 0.013).

\section{Discussion}

This is the first study demonstrating that the patients with planned ICU admission assessed after three months generally have a good memory of their health status as measured by EQ-5D in the period preceding surgery and ICU admission. This memory also appears to remain good after 6 months, because the values of ICC for EQ-5D recalled at 3 months and for EQ-5D recalled at 6 months in comparison with the pre-ICU EQ-5D were both higher than 0.8 , which is generally regarded as an excellent concordance [25]. On the other hand, the ICC for the EQ-VAS recalled was just acceptable at 3 months (0.648) and became lower at 6 months in comparison with the pre-ICU level (0.580). The reason for the different behaviour of EQ-5D and EQ-VAS may be strictly mathematical because the former is based on three possible answers (no problems; some/moderate problems; severe/extreme problems) for each of the EQ-5D items, while the latter is on a 101 point scale: the larger the scale parameter, the more spread out the distribution, and the higher the probability of making a different choice.

As far as methodological aspects are concerned, the study hospitals were located in two contiguous and similar Regions of Northern Italy, and the instrument used has been adopted in studies investigating different populations [26-28]. The TTO transformation of patients' EQ-5D was performed using data from a UK

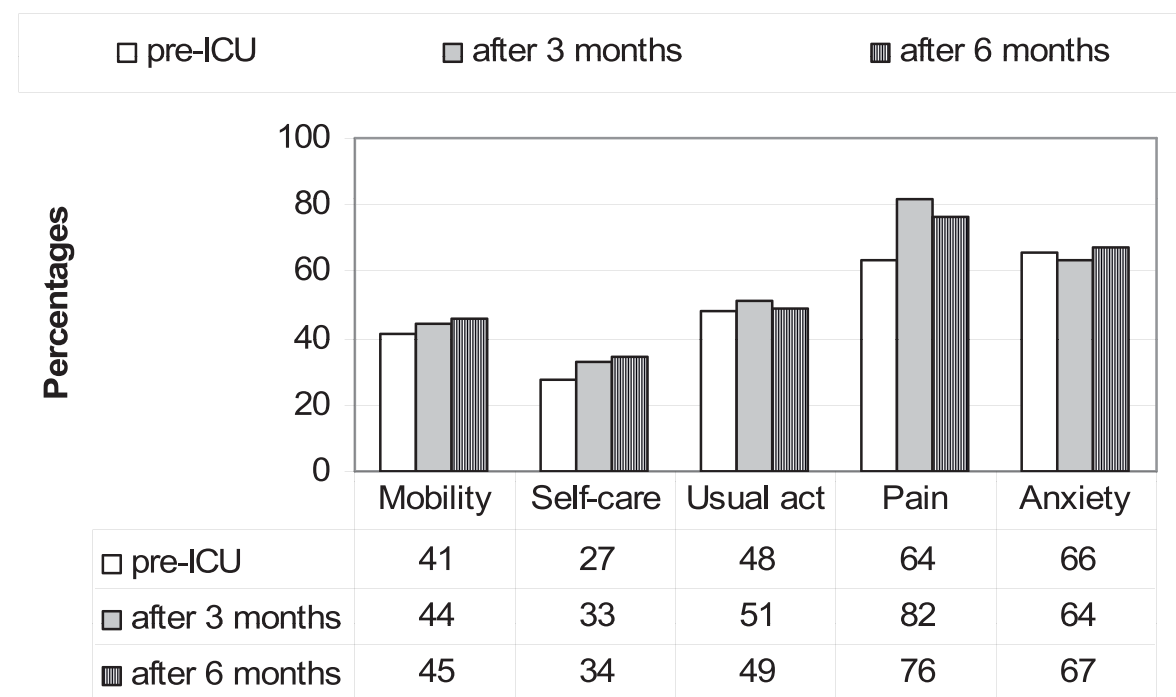

Figure 2 Percentages of patients reporting any problems in EuroQol-5D at the pre-ICU assessment, and recalling any problems at the assessments performed at 3 and 6 months. 
Table 2 Characteristics of the patients with ICU length of stay (LOS) $\leq 2$ and $>2$ days

\begin{tabular}{|c|c|c|c|}
\hline ICU length of stay & $\begin{array}{l}\leq 2 \\
\text { days }\end{array}$ & $\begin{array}{l}>2 \\
\text { days }\end{array}$ & $p$ \\
\hline Number of patients (\%) & $64(69)$ & $29(31)$ & \\
\hline Number of males (\%) & $41(64)$ & $23(79)$ & 0.157 \\
\hline Age, y: median $(I Q R)^{a}$ & $\begin{array}{l}74(66- \\
79)\end{array}$ & $\begin{array}{l}74(66- \\
77)\end{array}$ & 0.584 \\
\hline \multicolumn{4}{|l|}{ Education (\%): } \\
\hline$<8$ years & $17(27)$ & $16(55)$ & \\
\hline$\geq 8$ years & $47(73)$ & $13(45)$ & \\
\hline Use of any benzodiazepines (\%) & $8(12)$ & $3(10)$ & 1 \\
\hline Use of any antidepressants (\%) & $5(8)$ & $3(10)$ & 0.701 \\
\hline Use of any antihypertensive drugs (\%) & $55(86)$ & $23(79)$ & 0.544 \\
\hline Use of any B-blockers (\%) & $15(23)$ & $7(24)$ & 1 \\
\hline Use of any statins (\%) & $14(22)$ & $10(34)$ & 0.211 \\
\hline Smoking habits (\%): no & $36(56)$ & $19(65)$ & 0.453 \\
\hline Alcohol (\%): no & $22(34)$ & $9(31)$ & 0.656 \\
\hline \multicolumn{4}{|l|}{ Type of surgery (\%): } \\
\hline General & $9(14)$ & $10(34)$ & 0.064 \\
\hline Orthopaedic & $28(44)$ & $8(27)$ & \\
\hline Urologic & $27(42)$ & $11(38)$ & \\
\hline $\begin{array}{l}\text { Type of anaesthesia (\%): regional } \pm \\
\text { general }\end{array}$ & $13(21)$ & $6(21)$ & 0.814 \\
\hline general & & $51(79)$ & $23(79$ \\
\hline \multicolumn{4}{|l|}{ ICU and hospital course } \\
\hline SAPS I| median (IQR) ${ }^{a}$ & $\begin{array}{l}29(23- \\
39)\end{array}$ & $\begin{array}{l}31(26- \\
44)\end{array}$ & 0.309 \\
\hline Mechanical Ventilation in ICU (\%) & $24(37)$ & $17(58)$ & 0.073 \\
\hline $\begin{array}{l}\text { Mechanical Ventilation (hours) median } \\
(\text { IQR) }\end{array}$ & $8(3-8)$ & $\begin{array}{l}42(13- \\
88)\end{array}$ & 0.009 \\
\hline Delirium in ICU (\%) & 0 & $6(20)$ & 0.001 \\
\hline ICU LOS (days) median (IQR) & $1(1-2)$ & $1(1-3)$ & $\begin{array}{l}< \\
0.001\end{array}$ \\
\hline Hospital LOS (days) median (IQR) ${ }^{a}$ & $6(5-8)$ & $9(6-14)$ & 0.004 \\
\hline \multicolumn{4}{|l|}{ Follow-up at 3 months } \\
\hline Perceived severity of illness $>5(\%)^{b}$ & $14(22)$ & $9(31)$ & 0.437 \\
\hline PTSS-14 median (IQR) ${ }^{\mathrm{a}}$ & $\begin{array}{l}23(18- \\
30)\end{array}$ & $\begin{array}{l}26(20- \\
33)\end{array}$ & 0.088 \\
\hline HRQOL Comparison: worse (\%) & $21(33)$ & $13(45)$ & 0.378 \\
\hline \multicolumn{4}{|l|}{ Follow-up at 6 months (89 patients) } \\
\hline Perceived severity of illness $>5(\%)^{b}$ & $9(14)$ & $8(27)$ & 0.072 \\
\hline PTSS-14 median (IQR) ${ }^{\mathrm{a}}$ & $\begin{array}{l}23(18- \\
30)\end{array}$ & $\begin{array}{l}26(20- \\
33)\end{array}$ & 0.001 \\
\hline HRQOL Comparison: worse (\%) & $16(25)$ & $9(31)$ & 0.438 \\
\hline
\end{tabular}

P: statistical significance according to chi square test, except for age, SAPS II, ICU and Hospital length of stay, and PTSS-14 (Mann Withney test).

${ }^{a}$ IQR: Inter Quartile Range

${ }^{b}$ Perceived severity of illness assessed by Numerical Rating Scale 0 to 10.

population, so those for Italian people may be different. However, considering that the transformation was just used to analyse the statistical agreement - the concordance between the ratings of the same thing and period assessed at different points in time - also different

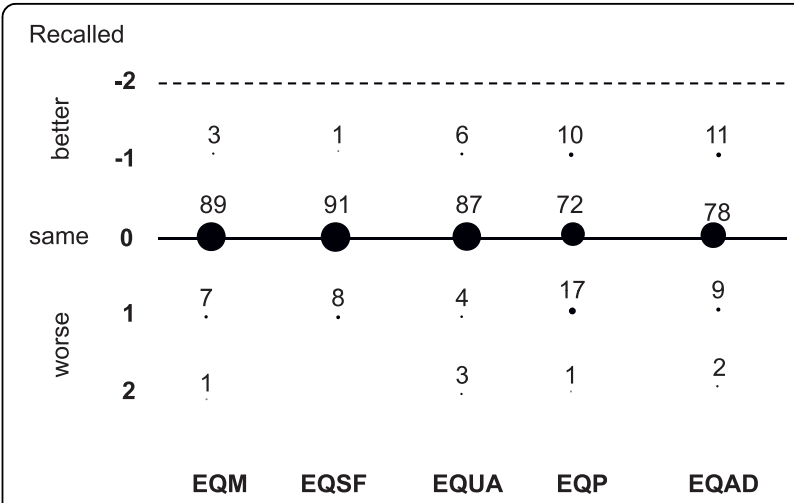

Figure 3 Differences between pre-ICU and 3-month recalled EuroQol-5D. Numbers are percentages of patients. EQ: EuroQol-5D. EQM mobility, EQSF self-care, EQUA usual activities, EQP pain/

discomfort, EQAD anxiety/depression

formulas to obtain TTO applied to all EQ-5D ratings would have given the same concordance.

Our findings agree with those of Guadagnoli et al. [12] who studied 1038 chest pain patients admitted to six hospitals for actual or suspected acute myocardial infarction and found substantial stability over time in response to individual items. The average difference between the scores assessed at the two times was significantly different from zero in only two cases; in both cases, patients reported that they were more functional before admission when asked at 3 months than when asked at the time of hospital stay. Accordingly, the EQVAS of our patients showed a slight trend towards increasing over time, suggesting that previous health status may be perceived better as time passes.

The information given by our study may be more useful than expected. In fact, most ICU admissions are unpredictable, so baseline HRQOL is usually measured according to the relatives' opinions [29]. Nevertheless,

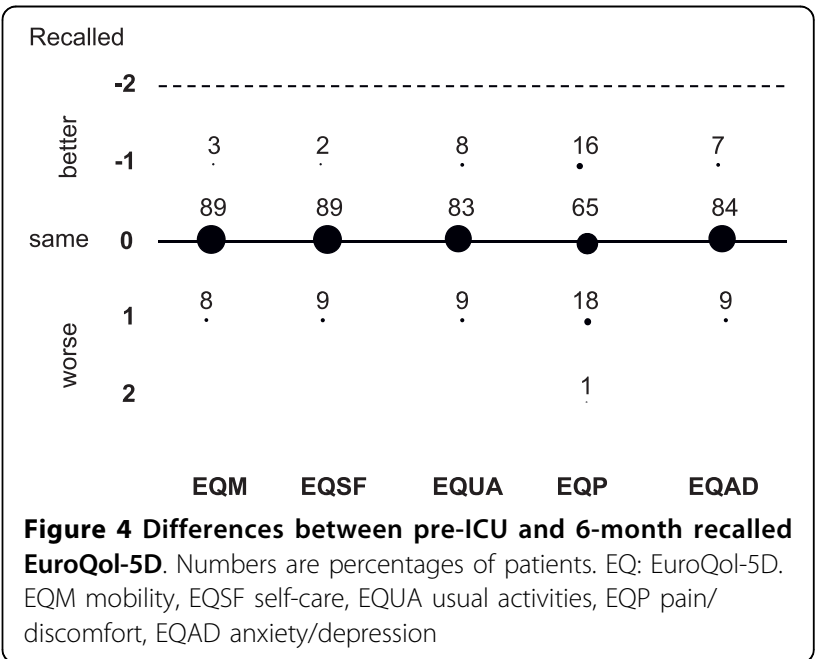


Table 3 Characteristics of the patients assessed at 3 months according to the comparison with the score given before surgery and ICU admission

\begin{tabular}{|c|c|c|c|}
\hline EQ-5D at 3 months vs pre-admission & same & different & $\mathrm{p}$ \\
\hline Number of patients (\%) & $42(45)$ & $51(55)$ & \\
\hline Number of males (\%) & $28(67)$ & $36(71)$ & 0.822 \\
\hline Age, y: median $(\mathrm{IQR})^{\mathrm{a}}$ & $\begin{array}{l}73(61- \\
80)\end{array}$ & $\begin{array}{l}74(67- \\
78)\end{array}$ & 0.389 \\
\hline \multicolumn{4}{|l|}{ Education (\%): } \\
\hline Education (\%): $<8$ years & $12(29)$ & $21(41)$ & 0.295 \\
\hline$\geq 8$ years & $30(72)$ & $30(59)$ & \\
\hline Use of any benzodiazepines (\%) & $3(7)$ & $8(16)$ & 0.334 \\
\hline Use of any antidepressants (\%) & $6(14)$ & $2(4)$ & 0.134 \\
\hline Use of any antihypertensive drugs (\%) & $36(86)$ & $42(82)$ & 0.780 \\
\hline Use of any B-blockers (\%) & $6(14)$ & $16(31)$ & 0.085 \\
\hline Use of any statins (\%) & $11(26)$ & $13(25)$ & 1 \\
\hline Smoking habits (\%): no & $12(29)$ & $13(25)$ & 0.921 \\
\hline Alcohol (\%): no & $25(60)$ & $24(47)$ & 0.322 \\
\hline \multicolumn{4}{|l|}{ Type of surgery (\%): } \\
\hline General & $5(12)$ & $19(37)$ & 0.011 \\
\hline Orthopaedic & $20(48)$ & $13(26)$ & \\
\hline Urologic & $17(40)$ & $19(37)$ & \\
\hline $\begin{array}{l}\text { Type of anaesthesia (\%): regional } \pm \\
\text { general }\end{array}$ & $11(26)$ & $8(16)$ & 0.302 \\
\hline general & $31(74)$ & $43(84)$ & \\
\hline \multicolumn{4}{|l|}{ ICU and hospital course } \\
\hline SAPS II median (IQR) ${ }^{a}$ & $\begin{array}{l}30(24- \\
45)\end{array}$ & $29(24-39)$ & 0.591 \\
\hline Mechanical Ventilation in ICU (\%) & $15(36)$ & $26(51)$ & 0.150 \\
\hline Delirium in ICU (\%) & $1(2)$ & $5(10)$ & 0.214 \\
\hline ICU LOS (days) median (IQR) & $2(1-2)$ & $2(1-3)$ & 0.203 \\
\hline Hospital $\operatorname{LOS}^{\mathrm{a}}$ (days) median (IQR) & $7(5-9)$ & $7(5-10)$ & 0.590 \\
\hline \multicolumn{4}{|l|}{ Follow-up at 3 months } \\
\hline Perceived severity of illness $>5(\%)^{b}$ & $5(12)$ & $18(35)$ & 0.009 \\
\hline PTSS-14 median (IQR) ${ }^{a}$ & $\begin{array}{l}25(18- \\
31)\end{array}$ & $24(20-31)$ & 0.685 \\
\hline HRQOL Comparison: worse (\%) & $14(33)$ & $20(39)$ & 0.711 \\
\hline
\end{tabular}

In the comparison between EQ-5D pre-admission and at 3 months "same" means that the scores at 3 months were the same while "different" means that at least one score at 3 months was different in at least one EQ-5D item in comparison with that before surgery and ICU admission.

P: statistical significance according to chi square test, except for age, SAPS II, ICU and Hospital length of stay, and PTSS-14 (Mann Withney test).

${ }^{a}$ IQR: Inter Quartile Range

b Perceived severity of illness assessed by Numerical Rating Scale 0 to 10 .

proxies may not accurately provide baseline measurements due to stress, infrequent contact with the patient, or different perceptions in comparison with the patient [30,31]. Diaz-Prieto et al [32] found kappas for patientproxy concordance ranging from 0.52 for mobility to 0.31 for anxiety/depression, without the effect of the type of patient/proxy relationship, or level of education or admission category (trauma, scheduled or unscheduled surgery, or medical). On the other hand, in the same study EQ-5D VAS scores obtained from patients and proxies correlated much better, with an ICC coefficient of 0.72, which is not so far from that found in the present study (0.648 at three months). Therefore, investigators interested in the before/after comparison of the quality of life of ICU patients may obtain a more reliable assessment of baseline health status interviewing the patients three or six months after discharge than interviewing the relatives.

The multivariate analysis showed that the ability to recall pre-ICU EQ-5D was poorer for general surgery patients at 3 and 6 months, and for urologic surgery patients at 6 months. Possibly, the sequelae of surgery or anti-neoplastic treatments, if required, may affect HRQOL memory in those patients, in comparison with orthopaedic surgery patients.

The similar ability to recall pre-ICU EQ-5D and EQ VAS showed by the patients with ICU LOS $\leq$ and $>2$ days suggests a limited effect of ICU stay on recall and gives strength to our study, despite the significant differences between the two patient groups in the incidence of delirium, hospital LOS and PTSS-14 at 6 months (Table 2). Considering 45 as cut-off for PTSS14 [18], only patients with ICU LOS $>2$ days had high values (one with 45 at 3 months and 24 at 6 months, and two with 45 and 50, respectively, at 6 months). Accordingly, we cannot exclude that the development of any PTSD symptoms may affect the recall of pre-ICU HRQOL. Interestingly, the chronic use of beta-blockers was associated with better ability to recall pre-ICU EQ$5 \mathrm{D}$, both at 3 and at 6 months. This findings agrees with a recent study showing that a pharmacological blockade of beta-adrenoceptors prevents glucocorticoidinduced memory retrieval deficits in human subjects [33]. A number of studies have examined the influence of giving a $\beta$-adrenergic receptor antagonist [34,35], to try to reduce the incidence of PTSD, however these therapies may be problematic in the critical care population and more research is needed to clarify their role.

As far as study limitations are concerned, our aim was to investigate stability of memory of HRQOL. Therefore, the only population suitable for the on time assessment before ICU admission consisted of patients with planned ICU admission. Consequently, it does not demonstrate that the findings reported are of value for patients with unplanned ICU admissions. Considering that DiazPrieto et al [32] found no relationship between patientproxy concordance and admission category, we may infer that our findings should be of general value. The exclusion of patients who were not admitted to ICU after surgery despite an admission planned at the time of the anaesthetic visit, allowed a homogeneous sample of patients with the same factors possibly influencing patient memory to be evaluated. In fact, the administration of analgesic and sedatives, which is a common ICU 
practice, has been demonstrated to influence patient memory of the ICU stay [36,37]. This practice may also influence the memory of the period preceding ICU admission, so we preferred to study the patients exposed to the same risk factors, that is those really admitted to ICU.

\section{Conclusions}

Patients with planned ICU admission have a good memory of their health status in the period preceding surgery and ICU admission. Their recall of EQ-5D appears to be good both at three and six months, being similar in the patients with different length of stay in ICU $(\leq$ or $>2$ days). Investigators may rely on the ICU patients' memory at 3 months.

\section{Acknowledgements}

The authors are indebted to Elena Toschi for her invaluable help in statistical analysis.

\section{Author details}

${ }^{1}$ University Section of Anaesthesiology and Intensive Care, Azienda Ospedaliero-Universitaria di Ferrara Arcispedale S. Anna, Ferrara, Italy. ${ }^{2}$ Department of Medical and Surgical Specialties, University Hospital of Florence, Florence, Italy. ${ }^{3}$ Department of Medicine, Surgery, and Critical Care, Section of Anaesthesiology and Intensive Care, University Hospital of Florence, Florence, Italy.

\section{Authors' contributions}

MC and SB conceived and designed the study. ED, GF, LP, and LT managed organisation and data collection. Data analysis was performed by $M C, S B$, $E D$, and GF. MC, SB, ED and GF wrote the draft of the report. All the authors contributed to the final writing of the report. RA performed the critical revision of the manuscript and supervision.

All authors read and approved the final manuscript.

\section{Competing interests}

The authors declare that they have no competing interests.

Some data have been reported in the thesis of Specialization in Anaesthesia and Intensive Care of one of the authors (GF) and the thesis won the award "Concorso Avant-Garde 2009" of the University of Pisa.

Received: 15 January 2010 Accepted: 16 September 2010 Published: 16 September 2010

\section{References}

1. Capuzzo M, Metnitz PGH, Moreno RP: Health related quality of life after ICU discharge. In 25 Years of Progress and Innovation in Intensive Care Medicine. Edited by: Kuhlen R, Moreno R, Ranieri M, Rhodes A. Berlin: MW Medizinisch Wissenschaftliche Verlagsgesellschaft; 2007:429-38.

2. Ridley SA, Chrispin PS, Scotton H, Rogers J, Lloyd D: Changes in quality of life after intensive care: comparison with normal data. Anaesthesia 1997, 52:195-202.

3. Wehler M, Geise A, Hadzionerovic D, Aljukic E, Reulbach U, Hahn EG, Strauss R: Health-related quality of life of patients with multiple organ dysfunction: individual changes and comparison with normative population. Crit Care Med 2003, 31:1094-1101.

4. Graf J, Koch M, Dujardin R, Kersten A, Janssens U: Health-related quality of life before, 1 month after, and 9 months after intensive care in medical cardiovascular and pulmonary patients. Crit Care Med 2003, 31:2163-9.

5. Cuthbertson BH, Scott J, Strachan M, Kilonzo M, Vale L: Quality of life before and after intensive care. Anaesthesia 2005, 60:332-339.

6. Badia X, Diaz-Prieto A, Gorriz MT, Herdman M, Torrado H, Farrero E, Cavanilles JM: Using the EuroQol-5D to measure changes in quality of life 12 months after discharge from an intensive care unit. Intensive Care Med 2001, 27:1901-1907.

7. Abelha FJ, Santos CC, Barros H: Quality of life before surgical ICU admission. BMC Surgery 2007, 7:23.

8. Capuzzo M, Moreno RP, Jordan B, Bauer P, Alvisi R, Metnitz PGH, on behalf of the SAPS 3 Investigators: Predictors of early recovery of health status after intensive care. Intensive Care Med 2006, 32:1832-8.

9. Dowdy DW, Eid MP, Sedrakyan A, Mendez-Tellez PA, Pronovost PJ, Herrige MS, Needham DM: Quality of live in adult survivors of critical illness: a systematic review of the literature. Intensive Care Med 2005, 31:611-620.

10. Grady KL: Beyond morbidity and mortality: quality of life outcomes in critical care patients. Crit Care Med 2001, 29:1844-1846.

11. Needham DM, Dowdy DW, Mendez-Tellez PA, Herridge MS, Pronovost PJ: Studying outcomes of intensive care unit survivors. Measuring exposures and outcomes. Intensive Care Med 2005, 31:1153-1160.

12. Guadagnoli E, Cleary PD: How consistent is patient-reported preadmission health status when collected during and after hospital stay? Med Care 1995, 33:106-112.

13. Folstein MF, Folstein SE, McHough PR: Mini Mental State: practical method for grading the cognitive status of patients for the clinician. J Psychiatr Res 1975, 12:189-98.

14. The EuroQol Group: EuroQol-a new facility for the measurement of health-related quality of life. Health Policy 1990, 16:199-208.

15. Brooks R, with the EuroQol Group: EuroQol: the current state of play. Health Policy 1996, 37:53-72.

16. Le Gall JR, Lemeshow S, Saulnier F: A new Simplified Acute Physiology Score (SAPS II) based on a European/North American multicenter study. JAMA 1993, 270:2957-63.

17. Ely W, Margolin R, Francis J, May L, Truamn B, Dittus R, Speroff T, Gautam S, Margolin R, Hart RP, Bernard GR, Inouye SK: Evaluation of Delirium in Critically III Patients: validation of the Confusion Assessment Method for the Intensive Care Unit (CAM-ICU). Crit Care Med 2001, 29:1370-1379.

18. Twigg E, Humphris G, Jones C, Bramweel R, Griffiths RD: : Use of a screening questionnaire for post-traumatic stress disorder (PTSD) on a sample of UK ICU patients. Acta Anaesthesiol Scand 2008, 52:202-208

19. Magni E, Binetti G, Bianchetti A, Rozzini R, Trabucchi M: Mini-mental state examination: a normative study in Italian elderly population. Eur J Neurol 1996, 3:1-5.

20. Dolan P: Modelling valuations for EuroQol health States. Med Care 1997, 35:1095-1108

21. Weijnen T, Nieuwenhuizen M, Ohinmaa A, de Charro F: Construction of the EQ-net VAS and TTO databases. In The measurement and valuation of the health status using EQ-5D: A European perspective. Edited by: Brooks R, Rabin R, de Charro F. Dordrecht, Nederlands: Kluwer Academic Publishers; 2003:55-79.

22. Garcia Lizana F, Peres Bota D, De Cubber M, Vincent J-L: Long-term outcome in ICU patients: what about quality of life? Intensive Care Med 2003, 29:1286-1293.

23. Granja C, Teixeira-Pinto A, Costa-Pereira A: Quality of life after intensive care-evaluation with EQ-5D questionnaire. Intensive Care Med 2002, 28:898-907.

24. Girard TD, Pandharipande PP, Ely EW: Delirium in the intensive care unit. Crit Care 2008, 12(Suppl 3):S3.

25. Fleiss JL: The measurement of interrater agreement. In Statistical methods for rates and proportions. Edited by: Fleiss JL. New York, Wiley, 2 1981:221-225.

26. Orwelius L, Nordlund A, Edéll-Gustafsson U, Simonsson E, Nordlund P, Kristenson M, Bendtsen P, Sjöberg F: Role of pre-existing disease in patients' perceptions of health-related quality of life after intensive care. Crit Care Med 2005, 33:1557-1564

27. Boer KR, van Ruler O, Reitsma JB, Mahler CW, Opmeer BC, Reuland EA, Gooszen HG, de Graaf PW, Hesselink EJ, Gerhards MF, Steller EP, Sprangers MA, Boermeester MA, De Borgie CA, the Dutch Peritonitis Study Group: Health related quality of life six months following surgical treatment for secondary peritonitis - using the EQ-5D questionnaire. Health Qual Life Outcomes 2007, 5:35.

28. Goldsmith KA, Dyer MT, Schofield PM, Buxton MJ, Sharples LD: Relationship between the EQ-5D index and measures of clinical outcomes in selected studies of cardiovascular interventions. Health Qual Life Outcomes 2009, 7:96. 
29. Hofhuis J, Hautvast JL, Schrijvers AJ, Bakker J: Quality of life on admission to the intensive care: can we query the relatives? Intensive Care Med 2003, 29:974-979.

30. Konopad E, Noseworthy TW, Johnston R, Shustack A, Grace M: Quality of life measures before and one year after admission to an intensive care unit. Crit Care Med 1995, 23:1653-1659.

31. Angus DC, Musthafa AA, Clermont G, Griffin MF, Linde-Zwirble WT, Dremsizov T, Pinsky MR: Quality adjusted survival in the first year after the acute respiratory distress syndrome. Am J Respir Crit Care Med 2001, 163:1389-1394.

32. Diaz-Prieto A, Gorriz MT, Badia X, Torrado H, Farrero E, Amador J, Abos R: Proxy-perceived prior health status and hospital outcome among the critically ill: is there any relationship? Intensive Care Med 1998, 24:691-8.

33. de Quervain DJ, Aerni A, Roozendaal B: Preventive effect of betaadrenoceptor blockade on glucocorticoid-induced memory retrieval deficits. Am J Psychiatry 2007, 164:967-9.

34. Vaiva G, Ducrocq F, Jezequel K, Averland B, Lestavel P, Brunet A, Marmar CR: Immediate treatment with propranolol decreases posttraumatic stress disorder two months after trauma. Biol Psychiatry 2003, 54:947-9.

35. Brunet A, Orr SP, Tremblay J, Robertson K, Nader K, Pitman RK: Effect of post-retrieval propranolol on psychophysiological responding during subsequent script-driven traumatic imagery in post-traumatic stress disorder. J Psychiatr Res 2008, 42:503-506.

36. Jones C, Griffiths RD, Humphris G, Skirrow PM: Memory, delusions, and the development of acute posttraumatic stress disorder-related symptoms after intensive care. Critical Care Med 2001, 29:573-580.

37. Capuzzo M, Valpondi V, Cingolani E, De Luca S, Gianstefani G, Grassi L, Alvisi R: Application of the Italian version of the Intensive Care Unit Memory tool in the clinical setting. Critical Care 2004, 8:R48-55.

doi:10.1186/1477-7525-8-103

Cite this article as: Capuzzo et al: Health-related quality of life before planned admission to intensive care: memory over three and six months. Health and Quality of Life Outcomes 2010 8:103.

\section{Submit your next manuscript to BioMed Central} and take full advantage of:

- Convenient online submission

- Thorough peer review

- No space constraints or color figure charges

- Immediate publication on acceptance

- Inclusion in PubMed, CAS, Scopus and Google Scholar

- Research which is freely available for redistribution

Submit your manuscript at www.biomedcentral.com/submit
Biomed Central 